\title{
A COBRANÇA DE HONORÁRIOS NA PRÁTICA CLÍNICA
}

\author{
Camile Gross* \\ Maycoln L. M. Teodoro**
}

\section{RESUMO}

A questão econômica na prática clínica é parte integral do processo psicoterapêutico. O presente estudo teve como finalidade investigar a percepção do processo da cobrança de honorários na prática clínica por psicoterapeutas de diferentes abordagens teóricas. Para tanto, foram entrevistados 12 psicólogas e um psicólogo atuando em psicologia clínica. Para o tratamento dos dados empregou-se a Análise de Conteúdo. A partir da concepção dos entrevistados sobre o tema da pesquisa, estabeleceram-se as categorias denominadas "Contrato", "Diferença entre a clínica privada-escola", "Honorários como parte do tratamento" e "Aprendizagem". Nos resultados desta pesquisa, as diferenças teóricas dos entrevistados não se destacaram. Os resultados apontam para as deficiências na formação acadêmica e profissional dos psicoterapeutas frente ao tema honorários em suas práticas clínicas e consequente despreparo referente a essa temática no início de sua vida profissional.

Palavras-chave: psicoterapia; honorários; preços.

\section{AbSTRACT}

FEE-CHARGING IN CLINICAL PRACTICE

Economic issues in clinical practice are part of the psychotherapeutic process. The objective of this study was to investigate the perceptions of psychotherapists from different theoretical approaches about fee-charging in psychotherapy. Twelve females and one male clinical psychologist were interviewed. Data were analyzed through content analysis. The following categories were established: "Contract"; "Difference between clinical-school and private practice"; "Fees as part of the treatment" and "Learning". Results of this research did not show any differences regarding the theoretical orientation of participants in all categories. Results point out to deficiencies in academic and

* Mestre em Psicologia pela Universidade do Vale do Rio dos Sinos (UNISINOS).

** Professor do Programa de Pós-Graduação em Psicologia da Universidade do Vale do Rio dos Sinos (UNISINOS). 
professional formation related to fee-charging and, consequently, to the psychologist's unpreparedness and lack of training regarding this thematic in the beginning of their professional life.

Keywords: psychotherapy; fees; charges.

Nos últimos anos, vêm sendo produzidos diversos artigos nacionais e internacionais sobre a relação estabelecida ao longo do processo da psicoterapia entre o psicólogo e o cliente. Estes trabalhos descrevem desde a importância do vínculo terapeuta-cliente para o sucesso da psicoterapia (Howard, Turner, Olkin \& Mohr, 2006), seu aparecimento em novas formas de intervenção, como a psicoterapia na internet (Prado \& Meyer, 2006), até as diferenças culturais existentes na sua formação (Vasquez, 2007). No entanto, alguns componentes desta relação vêm sendo negligenciados nos estudos acadêmicos, como a cobrança dos honorários. Este aspecto da relação deve ser investigado, já que o significado do dinheiro deve ser visto como objeto de discussão na relação entre psicoterapeuta e cliente, haja vista que a questão econômica é parte integral do processo psicoterapêutico (Tudor, 1998).

Para Dibella (1986) e Schonbar (1986) assuntos financeiros podem ser problemáticos para os clientes e para os psicoterapeutas porque poucas coisas além de questôes econômicas simbolizam de uma forma tão completa os conflitos emocionais. Para estes autores, existe, frequentemente, uma ligação direta entre a negligência dos assuntos relacionados ao dinheiro pelo terapeuta e as dificuldades em outras questôes do tratamento.

A falta de discussão sobre questões que envolvem honorários na relação terapêutica pode ocasionar sentimentos de culpa, de desvalorização do terapeuta e do tratamento, além do surgimento de impasses e até mesmo interrupçôes do mesmo (Eizirik, 1989). Lasky (1984) apresenta um estudo com 60 profissionais que exemplifica as dificuldades vivenciadas por psicoterapeutas e psicanalistas no estabelecimento de honorários. Os resultados apontam que dois terços da amostra pesquisada era particularmente atingida por esse dilema. Nessa pesquisa, foi comum a dualidade entre a vontade do profissional de ajudar as pessoas e a necessidade da remuneração. Muitos psicoterapeutas mencionaram o sentimento de desconforto frente à existência de um negócio, quando a sua principal motivação para este trabalho era prestar ajuda às pessoas.

Além das dificuldades citadas e exemplificadas por diversos estudos efetuados acerca do tema dos honorários na relação psicoterapêutica (vide Aubry \& Hunsley, 2000; Eizirik, 1989; Jacobs, 1986), convém acrescer outras que denotam as deficiências encontradas na graduação, as quais se refletem na prática dos psicólogos 
clínicos iniciantes e até mesmo dos mais experientes. Assim, uma pesquisa realizada pelo Conselho Federal de Psicologia em 1987 sobre o perfil do psicólogo brasileiro assinala que a formação complementar extrauniversitária do psicólogo clínico é constituída por um tripé formado por estudos teóricos, supervisões e análise pessoal e requer um vasto investimento temporal, financeiro e pessoal (Neto, 2004). É estimulado um caminho paralelo no aperfeiçoamento do psicólogo clínico, realizado geralmente por institutos, escolas ou associaçôes que representam distintos referenciais teóricos.

Nesta mesma perspectiva, Monger (1998) considera fundamentais o treino prático e o desenvolvimento pessoal na formação do terapeuta para a cobrança de honorários. A prática, supervisões e psicoterapia são meios que promovem a formação de uma melhor estrutura psicoterapêutica. Shields (1997) observa a necessidade de debater questôes sobre o pagamento durante a formação de psicoterapeutas, a fim de propiciar a autocrítica de aspectos ligados a assuntos financeiros na prática clínica.

Seguindo esta linha de raciocínio, Pasternack (1986) reforça a imperatividade do exercício de contratar honorários na relação psicoterapêutica, já a partir da formação universitária do profissional. Para este autor, deve fazer parte do treinamento em psicoterapia a supervisão criteriosa dos aspectos clínicos e administrativos das questões monetárias. Uma política de cobrança de honorários clara e firme apoia os estudantes em formação na habilidade de negociar valores monetários e outros aspectos da relação psicoterapêutica. Pasternack lembra ainda que a abrangência de assuntos financeiros na formação dos estagiários pode proporcionar um incremento na autoestima dos estudantes, tanto pela produção de renda quanto pela evolução dos casos em psicoterapia. Nesse sentido, o autor assinala que em programas educacionais de saúde mental deveria ser enfatizado o potencial dos benefícios de uma instrução que leve em conta assuntos monetários na psicoterapia.

Outra questão a se considerar é a trazida por Jacobs (1986), que adverte que o término prematuro do atendimento psicoterápico pode ocorrer pela dificuldade do psicoterapeuta em explorar o tema dos honorários e seu significado em supervisóes. Esse posicionamento reflete uma preocupação e a relevância desse tema para a formação profissional do psicoterapeuta, assim como sua incidência no próprio processo psicoterápico.

Dessa forma, a investigação dos honorários na prática psicológica possui muita relevância dentro da pesquisa clínica, uma vez que os sentimentos não resolvidos do psicoterapeuta e do cliente em relação à cobrança podem interferir no processo psicoterapêutico (Heller, Antunes \& Enck, 2004; Monger, 1998; Tudor, 
1998). Além disso, o tema é pouco explorado na formação desses profissionais, trazendo uma deficiência na prática clínica. Igualmente, é grande a escassez de material publicado sobre o assunto honorários na relação psicoterapêutica, e a maior parte das publicações existentes possui mais de vinte anos e é internacional (vide Gross \& Teodoro, no prelo).

O propósito do presente estudo foi investigar a percepção do processo da cobrança de honorários na prática clínica por psicoterapeutas de diferentes abordagens teóricas. Buscou-se compreender de que forma esses profissionais foram treinados e de que modo vivenciam, em sua prática clínica, a negociação de valores de honorários. Com esse trabalho objetivou-se também investigar como os psicoterapeutas estabelecem as regras dos honorários em sua prática e como percebem o significado de seu pagamento pelo cliente.

\section{MéTodo}

\section{PARTICIPANTES}

Participaram deste estudo 12 psicólogas e 1 psicólogo atuando em psicologia clínica. As características profissionais dos participantes estão descritas na Tabela em anexo.

Conforme descrito na Tabela, foram investigados cinco profissionais de Orientação Psicanalítica (OP), quatro da Abordagem Centrada na Pessoa (ACP) e quatro com experiência em Terapia Cognitiva Comportamental (TCC). Da totalidade dos profissionais entrevistados, 12 eram do sexo feminino e 1 do sexo masculino. Os critérios de inclusão para a participação nesse estudo foram atuar como psicólogo clínico e exercer atividade profissional remunerada na clínica psicológica.

\section{PROCEDIMENTOS DE PESQUISA E ÉTICOS}

O contato com os psicoterapeutas foi feito através de instituições de formação em psicoterapia e por indicação de colegas psicólogos. Estes indicaram novos possíveis participantes para o estudo, seguindo a técnica conhecida como "bola de neve". O procedimento foi realizado com cada profissional de forma individual em um único encontro, previamente marcado. As entrevistas foram gravadas para posterior transcrição e análise. Todos os participantes que concordaram em parti- 
cipar da pesquisa assinaram um Termo de Consentimento Livre e Esclarecido. Este estudo foi aprovado pelo Comitê de Ética em Pesquisa da Universidade do Vale do Rio dos Sinos (UNISINOS).

\section{PROCEDIMENTOS DE COLETA DE DADOS}

Os procedimentos utilizados para a coleta de dados foram um questionário e uma entrevista semiestruturada. O questionário com questôes sociodemográficas e laborais continha temas relativos tanto à identificação do participante (idade, sexo, linha teórica), quanto ao relato de suas atividades de trabalho (local, tempo de serviço, etc.).

A entrevista semiestruturada sobre os honorários teve como objetivo explorar as percepções do psicólogo clínico sobre este tema em sua prática. Os principais tópicos norteadores utilizados foram: a concretização do contrato terapêutico; os critérios para o estabelecimento da consulta; a negociação do valor do atendimento; os sentimentos dos profissionais ao tratar sobre o pagamento com o cliente; os significados atribuídos pelo psicoterapeuta frente ao recebimento ou não dos honorários e frente ao ato de pagar efetuado pelo cliente; a diferenciação de contratação do serviço entre a clínica-escola e a clínica privada; a abordagem do assunto honorários na prática clínica durante a formação e o papel do pagamento na evolução do processo terapêutico.

\section{ANÁLISE DOS DADOS}

As entrevistas foram analisadas por meio da Análise de Conteúdo, descrita em Bardin (2004). Todas as informaçōes fornecidas foram categorizadas e organizadas de acordo com a linha teórica do psicoterapeuta entrevistado. A primeira fase da Análise de Conteúdo, chamada de pré-análise, teve o intuito de organizar os dados inicialmente apontados, mas não de forma sistemática. A exploração do material, na segunda fase, foi caracterizada pela alocação de recortes do texto em unidades que foram dispostas em categorias. A última fase, denominada tratamento dos dados, teve como finalidade a interpretação dos resultados. A análise interpretativa foi efetuada por meio da inferência, que é um procedimento de dedução sobre elementos simbólicos e valorativos (Bardin, 2004). Desta forma, estabeleceram-se categorias indicadas pela concepção dos entrevistados sobre as questôes enfocadas na entrevista da pesquisa. 


\section{RESULTADOS E DISCUSSÃO}

A partir das respostas dos entrevistados acerca do tema honorários na relação psicoterapêutica, vislumbraram-se quatro agrupamentos de ideias, seguindo os passos descritos por Bardin (2004). As categorias foram denominadas Contrato; Diferença entre a clínica privada-escola; Honorários como parte do tratamento e Aprendizagem.

A categoria Contrato refere-se às combinações práticas realizadas entre o psicoterapeuta e o cliente para o ajuste do início do processo psicoterapêutico. Neste ajuste, incluem-se os dias e os horários de atendimento, os procedimentos relativos a faltas, férias e negociação do pagamento. Em relação ao estabelecimento do valor dos honorários, dois profissionais (TCC1 e TCC4) referiram que o ideal seria estipular o valor contratado já na primeira consulta: "o contrato terapêutico eu faço já na primeira sessão, no final da sessão eu vejo o valor com o cliente" (TCC4).

Por outro lado, todos os outros entrevistados entendiam que a combinação do valor a ser pago pelo cliente deveria ser feita no decorrer dos primeiros encontros e não necessariamente na primeira consulta: "eu espero para fechar um contrato financeiro depois que eu conhecer um pouquinho da realidade financeira da pessoa; por isso que eu não fecho na primeira” (OP4).

A exceção para estes casos era quando o próprio cliente trazia esta questão já na primeira consulta: "porque às vezes o cliente já chega querendo saber como é que funciona, quantas vezes por semana, quanto tempo que dura, quanto que ele vai pagar. Antes de qualquer coisa ele já chega falando do pagamento. E daí parece que enquanto eu não saciar isso, a gente não consegue ir para os finalmentes, então às vezes tem que se falar disso de cara” (ACP2).

Segundo Tudor e Worral (2002), o estabelecimento dos honorários deve ser concluído num acordo com o cliente antes do mesmo incorrer em compromisso ou responsabilidade de qualquer espécie. Igualmente no Brasil, o Código de Ética do Psicólogo (Conselho Federal de Psicologia, 2005), artigo 4º, letra $a$, recomenda que os psicólogos estabeleçam o valor do serviço prestado antes de iniciar o atendimento. Entretanto, na prática pode-se observar que usualmente os profissionais não seguem essa orientação. Pode-se vislumbrar através dos resultados obtidos que a maioria dos entrevistados fixa o valor de atendimento no decorrer das primeiras sessóes, visando o conhecimento da realidade da pessoa e priorizando as necessidades emocionais imediatas do cliente. Este resultado sugere que, na prática, existe uma maior atenção à realidade do cliente em detrimento dos interesses do psicoterapeuta. Por sua vez, este comportamento profissional estaria de acordo 
com o princípio descrito no Código de Ética do Psicólogo que refere que, no momento de acertar os honorários, o profissional deve levar em conta tanto a justa retribuição aos serviços prestados quanto a realidade do cliente.

Outra questão contratual enfocada pelos entrevistados dentro da categoria Contrato foram as faltas. A maioria deles (OP2, OP3, OP4, OP5, ACP2, ACP3, TCC3 e TCC4) computa-as no valor negociado, ainda que aceitem a possibilidade de compensá-las mediante novo horário. Convém ressaltar que o referencial teórico dos entrevistados não interferiu nos resultados encontrados nesse estudo, pois as respostas foram semelhantes, independente da linha teórica seguida pelo profissional.

Todavia, quatro dos treze psicoterapeutas entrevistados (ACP1, OP1, TCC1 e ACP4), quando avisados com antecedência de 24 h, não cobram a falta, ou seja, aceitam o cancelamento, e um dos psicoterapeutas cobra meia consulta (TCC2). $\mathrm{Na}$ circunstância de flexibilização das faltas, Monger (1998) e Tudor (1998) distinguem duas situações de pagamento: cancelamento ou falta. Também mencionam que alguns profissionais não cobram a sessão quando avisados com 24 horas de antecedência, enquanto outros o fazem. Por outro lado, houve consenso de respostas com relação à cobrança da sessão não realizada por falta. Nesse ponto, pareceu ser mais aceitável, para os psicoterapeutas, expressar sentimentos pessoais e o posicionamento da dependência de honorários para viver (Monger, 1998).

A partir destes resultados, pode-se inferir que a maneira encontrada pelos profissionais para garantir certa segurança em termos de estabilidade financeira na clínica privada é a cobrança das faltas mediante a possibilidade de compensação em novo horário. Isso garante o pagamento e ao mesmo tempo requer do cliente a responsabilidade por aquele horário e pelo seu processo psicoterapêutico. Convém salientar que essa solução é teoricamente conhecida pelos psicoterapeutas já na graduação, mas sua execução prática depende da experiência adquirida ao longo do trabalho clínico em razão da dificuldade dos iniciantes em cobrar honorários: "o que acontecia no início: a pessoa faltava e aí depois quando vinha me pagar pagava as sessōes que ela veio; e aí? Como é que eu vou cobrar? Agora, então isso é outra coisa que eu aprendi com o tempo a já fazer no contrato terapêutico, porque senão o que acontece? A gente não sabe quanto a gente vai ganhar no mês" (TCC4).

Em se tratando da quebra do contrato terapêutico por falta de pagamento, verificou-se entre os psicoterapeutas entrevistados a unanimidade em realizar a cobrança, mas com o cuidado de analisar esta questão caso a caso. Deste modo, o não pagamento de honorários poderia significar uma forma de defesa do cliente, numa tentativa de manter uma relação com o terapeuta na situação de término da 
psicoterapia. Por outro lado, a questão financeira no processo psicoterápico também pode representar sentimentos de hostilidade, culpa, desprezo, sedução, angústia ou a sensação de fragilidade (Stewart, 2005).

Os entrevistados, independentemente do referencial teórico, priorizaram a flexibilidade do contrato, havendo a possibilidade de renegociação do pagamento. Tudor (1998) enfatiza que as questôes relacionadas ao atraso ou esquecimento de pagamento de honorários dependem da postura de cada profissional. Alguns terapeutas lembram seu cliente ao final da sessão; outros utilizam a interpretação, confrontação de forma explícita; e, num outro extremo, deixam que o cliente se lembre. Estas questôes podem ser visualizadas nas falas seguintes:

eu costumo fazer assim: na última sessão de cada mês a gente acerta o pagamento (OP3).

cada caso é um caso. Tem alguns pacientes que eu digo assim, fulano, mês passado ainda não foi acertado, eu não sei se tu tem alguma previsão de quando isso vai ser feito (TCC4).

depende do cliente. Sinto quando o cliente está meio atrapalhado financeiramente, atrapalhado na vida; sei que ele vai atrasar uns dias, mas vai pagar, com esse não tem problema. Agora aquela pessoa que simplesmente some ou segue vindo e não toca no assunto, eu faço questão de mostrar que isso faz parte do processo também e que é um serviço e tem que ser pago (ACP2).

Também houve um consenso nas respostas dos entrevistados quanto à negociação dos honorários da consulta a partir das condições financeiras do cliente, embora os terapeutas tenham valores mínimos e máximos de consulta preestabelecidos. Os profissionais iniciantes na prática clínica, ao fixarem o valor de seus honorários, condicionaram a escolha do valor ao fato de serem novatos na profissão. A partir disso, pode-se inferir que é feita uma desvalorização do psicólogo clínico por ele mesmo e que há uma deficiência na formação desse profissional com relação ao conhecimento prático-teórico acerca de sua remuneração e valoração do seu trabalho: "normalmente eu digo qual é o valor que eu pego, por eu estar começando, eu pego o valor mais baixo da tabela do CRP. Que é uma sugestão de honorários que o conselho nos dá. Então eu pego aquilo ali e aquilo ali é a minha base" (ACP2).

No que diz respeito à categoria Diferença entre a clínica privada-escola, foram apontadas as peculiaridades do contratar honorários na relação psicoterápica dentro de um âmbito privado e institucional. Nas respostas dos entrevistados prevaleceu a opinião no sentido de que há diferença entre esses 
dois âmbitos (OP1, OP2, OP3, OP4, OP5, ACP1, ACP2, TCC1, TCC2, TCC3 e TCC4). A diferença está na interferência de um terceiro, no caso a clínicaescola da instituição, no processo. Basicamente, a alteração resume-se no fato de que nem todos os aspectos que envolvem o acordo de honorários são tratados direta e exclusivamente entre psicoterapeuta e cliente, como quando existe, por exemplo, um preço institucional:

tem diferença porque numa instituição, que seria uma escola, tem uma instituição como intermediária; aqui (clínica privada) sou eu que contrato, cobro e recebo diretamente (OP4).

eu acho que tem diferença porque quando tu estás numa clínica escola, tu estás respaldada por uma instituição, é norma da instituição. Uma coisa maior do que eu e tu; que determina isso; quando tu estás num consultório particular, sou eu quem determino; então não tem como se esconder atrás de nenhuma instituição (TCC4).

Corroborando o que foi exemplificado pelo relato acima, acrescenta-se o pensamento de Shields (1997), que sugere a necessidade de o próprio terapeuta lidar com questôes de honorários com seu cliente sem a interferência de terceiros. Nessa questão, Shields discute a formação de psicoterapeutas em treinamento, realizada cada vez mais em instituições e hospitais. Nestes locais, geralmente não é dada oportunidade ao profissional iniciante de tratar sobre questôes de pagamento de honorários diretamente com o cliente atendido. Assim, muitas vezes, o psicoterapeuta iniciante ingressa na prática clínica com pouco ou nenhum conhecimento sobre como lidar com honorários em relação ao cliente, sobre o significado do dinheiro, bem como sobre o aprendizado de operacionalizar a prática clínica como um negócio. Igualmente, o autor chama a atenção para a dificuldade dos psicoterapeutas em receber pagamento por ajudar alguém em sofrimento.

Honorários fazem parte do tratamento é uma categoria que abrange a percepção dos psicoterapeutas sobre os significados do recebimento dos honorários e do pagamento destes por parte dos clientes em função da relação psicoterapêutica. Por conta disso, essa relação naturalmente reflete e se movimenta com a influência desses significados singulares, ou seja, como cada um simboliza o recebimento e o pagamento dos honorários.

Os entrevistados foram questionados sobre a influência do tópico pagamento no processo psicoterápico e todos os participantes observaram que os honorários implicam o significado do dinheiro. Esse significado é singular e por isso deve ser visto como parte integral do processo psicoterapêutico. É o que se ilustra a seguir: 
se tem alguma pendenga em relação ao valor, seja para o terapeuta, seja para o cliente, que um dos dois não esteja de acordo, não tem como fluir; a base do processo psicoterapêutico é a relação (ACP2).

eu acho que a questão dos honorários diz sobre o paciente também, assim como o jeito como ele fala, como se veste; acho que os honorários também, o jeito como ele lida com o dinheiro (OP2).

sim, quando uso o comportamento do paciente em relação ao dinheiro como ferramenta para trabalhar com ele. No início eu não juntava a psicoterapia com o dinheiro, como se não pudesse fazer parte ajudar e cobrar (TCC2).

Reforçando a posição de que o pagamento dos honorários é parte integral da relação psicoterapêutica, Stewart (2005) assinala que questões financeiras podem dificultar o bom andamento do processo terapêutico. Esta influência negativa pode ocorrer devido ao aparecimento de constrangimento entre paciente e terapeuta, inclusive despertando ressentimentos e dificultando o aprofundamento de sua relação. A cobrança dos honorários e sua discussão dentro do contrato terapêutico são um assunto delicado e pode tomar proporçôes problemáticas no enquadramento clínico, inclusive para terapeutas mais experientes (Eizirik, 1989; Shields, 1997; Tudor \& Worral, 2002).

A discussão sobre o pagamento pode ter funções específicas no trabalho com o cliente, e explorar assuntos financeiros pode ser terapeuticamente útil. Stewart (2005) enfatiza que, em terapia, pode-se observar que a relação do cliente com o dinheiro está diretamente ligada a questôes do seu estilo de personalidade. Também nessa perspectiva, Power e Pilgrim (1990) apontam que terapeutas são enfáticos em reconhecer a importância do dinheiro, mas relutam em falar como esse assunto os afeta e as particularidades da sua prática clínica.

A categoria Aprendizagem é um quesito que envolve o desenvolvimento e a experiência do psicoterapeuta em estabelecer o valor das sessões para o seu atendimento clínico e para contratá-los junto ao cliente. A dificuldade em contratar honorários no início da prática clínica foi unânime entre os psicoterapeutas entrevistados. Os participantes mencionaram que o aprendizado sobre esse tema na sua formação acadêmica não foi explorado ou ocorreu de uma forma muito superficial e ineficaz para a prática profissional. Para os entrevistados, o aprendizado desse ponto foi constituído basicamente através da vivência da prática clínica privada, ou seja, posteriormente ao período de graduação profissional. Desta forma, os profissionais em início de carreira acabavam por não saber ou por ter dificuldades em valorar seu trabalho. Assim, existe a dificuldade de perceber a ideia do paga- 
mento como uma retribuição por uma prestação de serviço, bem como o pagamento de honorários como parte do tratamento, o que interfere e causa prejuízo no próprio processo psicoterapêutico, conforme pode ser observado nos recortes das falas a seguir:

hoje eu já tenho uma maior facilidade pra fazer isso, mas recém-formada era horrível, eu não conseguia nem dizer quanto que eu cobrava, e aí tem assim, me parece, um pouco da visão que se tem da profissão do psicólogo porque a gente vivencia isso também; parece que a gente tem que fazer o bem, e pra fazer o bem não se pode cobrar; uma coisa assistencialista, e isso perpassa a nossa formação (TCC4).

já foi bem difícil pra eu cobrar; hoje é normal, eu acho que foi um aprendizado (ACP1).

se falava em fazer o contrato, mas não era dito como se fazia (era como se estivesse entendido exatamente o que era fazer o contrato); em nenhum momento foi abordado honorários (TCC3).

eu não tinha nem ideia de quanto eu cobraria quando saísse da faculdade; é um assunto que tem que ser abordado (OP3).

contatava com os colegas pra saber como e quanto estavam cobrando, para aliviar a culpa. Sentia como psicoterapeuta envolvida com o cliente tendo dificuldade em trazer o tema honorários na relação (TCC2).

$\mathrm{Na}$ formação desses profissionais, o assunto honorários é muito pouco explorado, trazendo uma deficiência na prática clínica. Do mesmo modo, há carência desse tópico em planos de ensino e cursos de formação de psicoterapeutas (Aubry \& Hunsley, 2000; Monger, 1998; Shields, 1997; Tudor, 1998). Nesse ínterim, Tudor e Worral (2002) salientam que os psicoterapeutas com pouca experiência, embora atuantes em sua profissão, geralmente sentem-se inseguros frente ao seu sustento e muitos se veem obrigados a trabalhar em outras áreas para manterem seus rendimentos. Igualmente, referem que os psicoterapeutas iniciantes enfrentam dificuldades nos cursos de treinamento. Os mesmos autores alertam também para as situações em serviços voluntários, em que psicoterapeutas iniciantes, a fim de concorrerem à aquisição do espaço de trabalho com colegas experientes e qualificados, sujeitamse a uma não remuneração. Tal situação acarreta prejuízo, tanto para os profissionais experientes, quanto para os em treinamento.

A partir dos resultados encontrados neste estudo, pode-se perceber que no processo de treinamento de psicoterapeutas iniciantes não há um espaço formal 
destinado ao aprendizado de contratação de honorários. Consequentemente, os psicoterapeutas iniciam sua vida profissional sem terem claras suas questões em relação ao dinheiro, e com dificuldades em enfocar este tema com os clientes.

\section{CONSIDERAÇÕES FINAIS}

A presente investigação trouxe algumas reflexões no que se refere à formação acadêmica e profissional dos psicólogos. Nos resultados das entrevistas todos os participantes relataram que no início de sua vida profissional sentiam-se despreparados quanto ao tema honorários na sua prática clínica e que esse assunto foi inexistente em sua graduação ou contemplado de forma superficial. A partir disso, pode-se ventilar a ideia de um estigma presente no curso de Psicologia frente à prestação da ajuda psicológica desvinculada da noção de que se trata também de uma prestação de serviço, ou seja, de que é um trabalho que está sendo realizado e que deve ser remunerado.

Com base nos resultados das entrevistas também se verificou que cada entrevistado aprendeu a valorar seu serviço e a contratá-lo com o cliente por meio da experiência na prática profissional. Assim, além das dificuldades naturais de um início de carreira, a ausência de discussão sobre este tema na graduação prejudica a entrada do profissional no mercado de trabalho.

As diferenças teóricas dos entrevistados não se destacaram nos resultados encontrados neste estudo, pois muitos posicionamentos foram unânimes entre os entrevistados, inclusive as dificuldades encontradas frente ao assunto honorários em suas práticas clínicas. Em duas (Honorários fazem parte do tratamento e Aprendizagem) das quatro categorias elencadas nessa pesquisa houve, inclusive, uma equivalência nas respostas dadas pelos representantes das três linhas teóricas.

A presente pesquisa não esgota a possibilidade de futuros estudos com esta temática. Neste sentido, espera-se que os resultados desta investigação contribuam para um alerta sobre a deficiência na formação dos psicoterapeutas em relação ao tema dos honorários e para fomentar os estudos nessa área. Cabe ressaltar que se deve ter cuidado sobre percepçōes generalizadas sobre este estudo, devido ao caráter exploratório do mesmo. Assim, leva-se em consideração o fato de a amostra desta pesquisa não contemplar todos os referenciais teóricos existentes na psicologia clínica. Deve-se também considerar que a amostra desta pesquisa foi composta por psicoterapeutas da região metropolitana de Porto Alegre e que, na sua distribuição, dentre todos os participantes, somente um era do sexo masculino. 


\section{REFERÊNCIAS BIBLIOGRÁFICAS}

Aubry, T. D. \& Hunsley, J. (2000). Quid pro quo: Fee for services delivered and a psychology training clinic. Journal of Clinical Psychology, 56, 23-31.

Bardin, L. (2004). Análise de conteúdo. Lisboa: Edições 70.

Conselho Federal de Psicologia (2005). Código de ética profissional do psicólogo. Resolução CPF n ${ }^{\circ}$ 010/05, de 21 de julho de 2005. Brasília: CFP.

Dibella, A. G. (1986). Money issues that complicate treatment. In: Krueger, D. W. (ed.). The last taboo: money as symbol and reality in psychotherapy and psychoanalysis (pp. 102110). New York: Brunner/Mazel.

Eizirik, L. C. (1989). Psicoterapia de orientação analítica. Porto Alegre: Artmed.

Gross, C. \& Teodoro, M. L. M. (no prelo). A cobrança dos honorários na prática clínica por psicoterapeutas: uma revisão de literatura. Aletheia.

Heller, G.; Antunes, A. C. \& Enck, N. M. E. (2004). Qual o valor da consulta? Revista da Sociedade Brasileira de Psicanálise de Porto Alegre, 6, 19-29.

Howard, I.; Turner, R.; Olkin, R. \& Mohr, D. C. (2006). Therapeutic alliance mediates the relationship between interpersonal problems and depression outcome in a cohort of multiple sclerosis patients. Journal of Clinical Psychology, 62, 1197-1204.

Jacobs, H. D. (1986). On negotiating fees with psychotherapy and psychoanalytic patients.

In: Krueger, D. W. (ed.). The last taboo: money as symbol and reality in psychotherapy and psychoanalysis (pp. 121-131). New York: Brunner/Mazel.

Lasky, E. (1984). Psychoanalysts' and psychotherapists' conflicts about setting fees. Psychoanalytic Psychology, 1, 289-300.

Monger, J. (1998). The gap between theory and practice. Psychodynamic Counseling, 4, 93-107.

Neto, J. L. F. (2004). A formação do psicólogo: clínica, social e mercado. São Paulo: Escuta. Pasternack, A. S. (1986). Psychotherapy fees and therapist training. In: Krueger, D. W. (ed.). The last taboo: money as symbol and reality in psychotherapy and psychoanalysis (pp. 142-157). New York: Brunner/Mazel.

Power, L. C. \& Pilgrim, D. (1990). The fee in psychotherapy: practitioner's accounts. Counseling Psychology Quarterly, 3, 153-171.

Prado, O. Z. e Meyer, S. B. (2006). Avaliação da relação terapêutica na terapia assíncrona via internet. Psicologia em Estudo, 11, 247-257.

Schonbar, A. R. (1986). The fee as focus of transference and countertransference in treatment. In: Krueger, D. W. (ed.). The last taboo: Money as symbol and reality in psychotherapy and psychoanalysis (pp. 33-47). New York: Brunner/Mazel.

Shields, D. J. (1997). Prisioneiros do pagamento: o dinheiro, a transferência e o terapeuta iniciante. Mudanças, 5, 235-266. 
Stewart, S. N. (2005). Considering fees in psychodynamic psychotherapy: opportunities for residents. Academic Psychiatry, 29, 21-28.

Tudor, K. (1998). Value for money? Issues of fees in counseling and psychotherapy. British Journal of Guidance e Counseling, 26, 477-494.

Tudor, K. e Worral, M. (2002). The unspoken relationship: financial dynamics in freelance therapy. In: Clark, J. (ed.). Freelance counseling and psychotherapy (pp. 80-90). East Sussex: Brunner-Routledge.

Vasquez, M. J. T. (2007). Cultural difference and the therapeutic alliance: an evidencebased analysis. American Psychologist, 62, 878-885.

\section{ANEXo}

\section{TABELA}

\begin{tabular}{|lcccc|}
\hline Identificação & Linha Teórica & Sexo & $\begin{array}{c}\text { Tempo de } \\
\text { Experiência }\end{array}$ & $\begin{array}{c}\text { Idade } \\
\text { (anos) }\end{array}$ \\
\hline OP 1 & Orientação Psicanalítica & Feminino & 7 anos & 32 \\
OP 2 & Orientação Psicanalítica & Feminino & 15 anos & 38 \\
OP 3 & Orientação Psicanalítica & Feminino & 4 anos & 26 \\
OP 4 & Orientação Psicanalítica & Feminino & 6 anos & 29 \\
OP 5 & Orientação Psicanalítica & Feminino & 16 anos & 41 \\
ACP 1 & Abordagem Centrada na Pessoa & Feminino & 9 anos & 39 \\
ACP 2 & Abordagem Centrada na Pessoa & Feminino & 3 anos & 28 \\
ACP 3 & Abordagem Centrada na Pessoa & Feminino & 15 anos & 47 \\
ACP 4 & Abordagem Centrada na Pessoa & Masculino & 15 anos & 48 \\
TCC 1 & Terapia Cognitiva Comportamental & Feminino & 3 anos & 33 \\
TCC2 & Terapia Cognitiva Comportamental & Feminino & 4 anos & 31 \\
TCC3 & Terapia Cognitiva Comportamental & Feminino & 4 anos & 45 \\
TCC4 & Terapia Cognitiva Comportamental & Feminino & 4 anos & 30 \\
\hline
\end{tabular}

Recebido em 25 de fevereiro de 2009 Aceito para publicação em 14 de junho de 2009 